\title{
SISTEMAS QUÍMICOS: DISCUSSÕES E MÉTODOS APLICADOS NA RESOLUÇÃO DE PROBLEMAS
}

\author{
Antonio Barros de Souza ${ }^{1}$ \\ Francisca Raniely Domingos ${ }^{2}$
}

\begin{abstract}
Resumo: Dentro da resolução de problemas subentende-se que é a uma resposta ou a solução para um determinado problema que ainda não tenha uma solução apresentada, seja um problema de contexto escolar ou do cotidiano onde serão necessários conhecimentos prévios para encontrar a solução do problema do assunto que nesse caso são sistemas químicos. Este trabalho é de caráter descritivo, com revisão de literatura baseada em pesquisas bibliográficas com espelhamento em pesquisa de Campo, foi realizado oficinas de Química com os alunos da escola municipal Afonso Tavares de Luna, localizada na zona rural de Brejo Santo-CE, onde os alunos tiveram a oportunidade de aprender conteúdos e produzir uma garrafa térmica artesanal que conserva a temperatura da água por mais tempo . O projeto foi de grande importância para os alunos do ensino fundamental da e também para os alunos do curso interdisciplinar em Ciências Naturais da UFCA que aprimoraram sua prática docente.
\end{abstract}

\section{CHEMICAL SYSTEMS: DISCUSSIONS AND METHODS APPLIED IN TROUBLESHOOTING}

\begin{abstract}
Within the problem solving it is understood that it is a response or solution to a given problem that does not have a solution presented, whether it is a problem of school context or daily life where previous knowledge is needed to find the solution to the problem of the subject in this case are chemical systems. This work has a descriptive character, with literature review based on bibliographical researches with mirroring in field research. Chemistry workshops were carried out with the students of the Afonso Tavares de Luna municipal school, located in the rural zone of Brejo Santo-CE, where the students had the opportunity to learn content and produce a homemade thermal bottle that conserves the water temperature for longer. The project was of great importance for students of elementary school as well as for the students of the interdisciplinary course in Natural Sciences of UFCA who improved their teaching practice.
\end{abstract}

\footnotetext{
${ }^{1}$ Discentes do Programa de pós-graduação em desenvolvimento regional sustentável da UFCAPRODER;
} 


\section{Introdução}

Sistemas são porções limitadas do universo, ou seja, uma amostra, como exemplo: um copo de água, um vidro de perfume, ou qualquer outro tipo de amostra armazenada em um recipiente, os sistemas podem ser considerados para estudo, sendo possível observar e experimentar. Como exemplo a substância de $\mathrm{H}_{2} \mathrm{O}$ é separada uma porção da substância a qual é chamado de sistema.

Os sistemas podem ser classificados em homogêneos e heterogêneos, os homogêneos apresentam as mesmas propriedades em toda a sua extensão, já os sistemas heterogêneos caracterizam-se pela oscilação entre os seus elementos, sendo classificados em dois grupos: abertos e fechados - os sistemas abertos realizam trocas de energias de massa com os meios externos, interagindo com propriedades fora da sua superfície, já nos sistemas fechados (ou isolados) também chamados de adiabáticos ${ }^{2}$, não ocorrem trocas de energias de massas.

É comum em muitas escolas os alunos utilizarem garrafas pet para armazenar água, o recipiente (garrafa) onde a água está armazenada pode ser caracterizado como um sistema aberto ou fechado, podendo acontecer a troca de energia de massas e consequentemente modificar a temperatura da substância do sistema, ou seja, nesse caso a água corre o risco de esquentar, tendo o seu uso inviabilizado, e, gerando o desperdício, tornando-se assim um problema para sociedade em geral.

Este trabalho teve como objetivo descrever os métodos utilizados na resolução de problemas, apresentando os sistemas químicos e as suas composições, com ênfase na aplicação didática destes métodos, através de exemplos práticos

\section{Fundamentos teóricos}

Na discussão sobre resolução de problemas, pode ser possível fundamentar a Metodologia de Ensino-Aprendizagem-Avaliação de Química através da Resolução de Problemas:

Na Didática das Ciências, as investigações envolvendo a resolução de problemas são abordadas a partir de perspectivas diversas: psicologia

\footnotetext{
2 Discentes do Curso de Licenciatura Interdisciplinar em Ciências Naturais e Matemática
} 
cognitiva, epistemologia, processamento da informação, lógica de cada disciplina, filosofia da ciência, etc. (MARTIN, 1991; PALACIOS, 1993).

No ensino de química bem como as Ciências Naturais, a resolução de problemas pode ser vista em um formato de multidisciplinaridade, envolvendo também questões cotidianas, através de problemas que envolvam a química e interliguem ao dia a dia as necessidades básicas do aluno.

O aluno sabendo no que vai aplicar aquele conteúdo no cotidiano motiva-se a aprender e procurar a solução para determinado problema, sendo assim partindo para um campo de investigação onde ele vai partir de dados ou conhecimentos prévios tendo assim competências para desenvolver o problema e chegar à solução.

As críticas às investigações baseadas nos especialistas e principiantes apontam para a perspectiva de transmissão verbal de conhecimentos já elaborados, a qual é reconhecidamente ultrapassada mostrando-se, nas últimas décadas, um modelo insuficiente (RAMÍREZ CASTRO, GILPÉREZ; MARTINEZ TORREGROSA, 1994 apud FREIRE; SILVA JÚNIOR; SILVA, 2011, p. 115).

Tendo em vista os métodos propostos por alguns estudiosos para resolução de problemas é viável reconhecer novos métodos e novas formas de resolver problemas relacionados a conteúdos de Química e também fazer uma discussão teórica e prática dentro do contexto das ciências se aplique, pois quando se tem uma aplicabilidade tem um intuito maior de se chegar a uma resposta exata.

Ramalho (2008) afirma que o professor de ciências naturais da disciplina de Química ou de alguma das ciências, precisa buscar cada vez mais, conhecimento tanto teórico como práticos e tentar adaptar os problemas, ou seja, fazer o possível para modelar os problemas trazendo para realidade para que os alunos possam resolver problemas modelados e assim possam até outros problemas por meio de experimentos. Os experimentos podem servir para a finalidade de propor mais um recursos didático onde torna o ensino com mais qualidade para o próprio aluno, mostrando que essas fermentas são necessárias, mais não suficiente para a resolução de todos os problemas para um bom aprendizado.

O professor precisa ter a humildade para reconhecer que precisa cada dia evoluir para acompanhar as mudanças do cotidiano, devendo atentar para as alterações dos métodos de ensino em face da inovação tecnológica e das necessidades reais de seus 
alunos. Nessa perspectiva, devemos considerar que o ensino está em um constante processo de mudanças teóricas e onde um processo que interligado a conceitos que possam auxiliar na resolução de problemas de química também.

Segundo Paulo Freire (2008), o professor deve suscitar nos estudantes o espírito crítico, a curiosidade, a não aceitação do conhecimento simplesmente transferido. Os educadores têm "como uma de suas tarefas primordiais (...) trabalhar com os educandos a rigorosidade metódica com que devem se aproximar dos objetos cognoscíveis".

Nessa perspectiva o método de resolução de problema pode ser mediado por diversas correntes onde, pode entender um contexto teórico e prático agregando conhecimentos da química que no presente trabalhos aos sistemas químicos como utilizar ou se beneficiar de contexto em solucionar um problema teórico e um problema prático, ou seja, um problema de modelagem na química.

Com isso não adianta entender só etapas de resolver um problema é preciso ter conhecimentos prévios que também podem ser chamados de pista fazendo a união dessas pistas obtêm-se um conhecimento maior e chegar à solução de uma maneira mais fácil.

Como foco de discussão e não apenas de aplicação de um método de resolução de problemas como em outras disciplinas na Química é necessário discutir e propor também novos meios de como chegar à resolução de um determinado problema, partindo de conhecimentos diversificados em contexto ou concordância teórica.

A resolução de problemas segundo Polya(1995) pode ser através quatro etapas de solução de problemas, especificamente com o conteúdo de sistemas químicos:

$1^{a}$ etapa: Compreender o problema: Nesta etapa é importante fazer perguntas, identificar qual é a incógnita do problema, verificar quais são os dados e quais são as condições entre outros.

Na Química também pode ser aplicado essa etapa no nosso projeto as perguntas podem ser O professor pode começar fazendo a pergunta o que é sistema? Para que os alunos possam expor seus conhecimentos prévios sobre o que é um sistema. Surgirão diversas respostas sobre sistemas, se nenhum aluno falar de sistema químico. $O$ professor poderá fazer uma nova pergunta: O que é um sistema químico? Se os alunos desconhecer o que é um sistema químico o professor explica o que é um sistema químico, exemplifica com algo relacionado ao cotidiano deles para que facilite a 
compreensão, e se tiver outra oportunidade poderá refazer a pergunta em outro momento para que os alunos consolidem os conhecimentos sobre o assunto.

$2^{\mathbf{a}}$ etapa: Construção de uma estratégia de resolução: Nesta etapa devemos encontrar as conexões entre os dados e a incógnita, caso seja necessário considerando problemas auxiliares ou particulares.

Nesta etapa o professor explica cada tipo de sistema químico fazendo demonstrações expositivas com slide de imagens, ou também se tiver a disposição mostrar em recipientes, como um copo com água, garrafa pet, garrafa térmica. Isso ficando a critério do professor como um segundo plano caso haja imprevistos

$3^{a}$ etapa: Execução da estratégia: Frequentemente, esta é a etapa mais fácil do processo de resolução de um problema. Contudo, a maioria dos principiantes tende a pular esta etapa prematuramente e acabam se dando mal.

Esse é o momento que o aluno vai determinar as fazes e os componentes do sistema e classificar o sistema.

$4^{\text {a }}$ etapa: revisando a solução: Exame da solução obtida e verificação dos resultados e dos argumentos utilizados.

Revisar os problemas, as estratégias e expor os resultados. Fazendo a análise dessas etapas percebe que ela pode inserida na resolução de problemas químicos também.

\section{Procedimentos metodológicos}

O projeto foi aplicado com os alunos da escola Afonso Tavares de Luna entre eles 10 alunos do $8^{\circ}$ ano B e 14 alunos do $9^{\circ}$ ano $\mathrm{A}$ e B. As aulas foram com rodas de conversas onde os alunos da UFCA, ministraram uma aula teórica com a interação dos alunos da escola onde o intuito era contextualizar o que era Química, sistemas e sistemas químicos bem como identificar cada sistema e apresentar a solução para alguns problemas que envolvesse a temática.

Depois foi aplicada uma atividade escrita sobre a temática onde os alunos tiveram que resolver problemas e expor suas respostas para toda a turma; consolidada essa parte teórica foi transmitido um vídeo ensinando a fazer uma garrafa térmica a 
partir de garrafas pet papel alumínio e jornal, para finalizar foi construída algumas garrafas em equipes que no final foram apresentadas pelos os membros de cada equipe.

\section{Resultados obtidos}

O projeto Sistemas químicos: Discussões e Métodos aplicados na resolução de problemas foi desenvolvido pelos discentes: Antonio Barros de Souza, Francisca Raniely Domingos do Curso de graduação Interdisciplinar em Ciências Naturais e Matemática da Universidade Federal do Cariri, sob orientação dos professores: Me. Rochelande Felipe Rodrigues, Me.Laura Hévila Inocencio Leite, Dr.Edicarlos Pereira Sousa.

A escola que foi escolhida para ser desenvolvido o projeto foi a escola municipal Afonso Tavares de Luna, localizada no sitio Timbaúba município de Brejo Santo - Ce. A Escola Afonso Tavares de Luna foi fundada em 1979, pelo prefeito Juarez Sampaio por uma promessa política a comunidade. Em 1984 foi aprovada a lei de aprovação da escola, Lei no .135 de 24 de setembro de 1984.

Inicialmente a escola contava com uma estrutura pequena e tinha só ensino fundamental I, sendo coordenada apenas pelos professores, em 1999 o professor Pedro Pereira Neto assumiu a direção da escola, o qual permanece até hoje, juntamente com as coordenadoras Tereza Cristina Genuíno, Adriana Florêncio, a escola hoje conta com 14 salas de aulas ,além de dois polos de extensão, 1086 alunos são beneficiados com o ensino da escola, sendo 6 turmas de ensino infantil, 12 turmas de ensino fundamental I e 11 turmas de ensino fundamental II, o ensino da escola é considerado bom sendo uma das melhores escola municipal de Brejo Santo.

Na perspectiva educacional fica notória que este projeto teve grande relevância para o ensino de Ciências na escola Afonso Tavares de Luna, bem como para o ensino aprendizagem e a compreensão do conteúdo teórico sistemas químicos com a resolução de problemas.

O foco principal do projeto foi a resolução de problemas com os sistemas químicos, só que, além disso, o projeto trabalhou também com outras tendências. Inicialmente com aporte teórico do conteúdo foi possível os alunos identificarem os sistemas químicos no seu cotidiano, apresentando e reconhecendo os problemas e 
também a possibilidade de resolver problemas teórico com a identificação dos sistemas abertos, fechados, adiabáticos e quando homogêneos ou heterogêneos saber também identificar as fases e componentes presentes nos sistemas, onde fica caracterizado o método de resolução de problema, já com o problema do cotidiano nota-se que é trabalhado a modelagem que é uma tendência que ajuda muito o aluno a compreender o conteúdo melhor e também partirmos para a parte de experimentar que era construir uma garrafa térmica com garrafa pet, onde os alunos mostraram-se muito dedicados na construção e também demonstravam que realmente tinham compreendido o conteúdo e o projeto foi de grande importância para os alunos do ensino fundamental da escola Afonso Tavares de Luna e também para os alunos do curso interdisciplinar em Ciências Naturais da UFCA que aprimoraram sua prática docente.

\section{Considerações finais}

O desenvolvimento deste trabalho com os alunos da escola Afonso Tavares de Luna permitiu constatar que para o ensino de Ciências e condução de uma formação de qualidade é necessário que se promova o dialogo nas esferas educacional, e assim a inserção da interdisciplinaridade no ensino.

O projeto também nos permitiu vivenciar experiências distintas com projetos relacionados à mesma temática e assim destacar a importância da interdisciplinaridade no ensino fundamental.

\section{Referências}

FREIRE, M. S.; SILVA JÚNIOR, G. A.; SILVA, M. G. L. Panorama sobre o tema resolução de problemas e suas aplicações no ensino de química. Acta Scientiae, Canoas, v.13, n.1, jan./jun. 2011, p. 106-120.

FREIRE, P. Pedagogia da autonomia: saberes necessários à prática educativa. 33 . ed. Rio de Janeiro: Paz e Terra, 2006.

GIL PÉREZ, D. Contribuição da história e filosofia da ciência desenvolvimento um modelo de ensino / aprendizagem e pesquisa. Educação científica,v.11, n.2, p.197-212, 1993.

MARTIN, J. V. R. Solução de problemas de química como a investigação: uma baseada proposta didática na mudança metodológica. 1991, 411 f. Tese (Doutorado 
em ciências químicas) - Faculdade de Ciências, Departamento de Química Física da Universidade do País Basco, de 1991.

PERALES PALACIOS, F. J.; Canal, P. (Orgs.). Ensino de Ciências Experimental. Barcelona: Ivory de 2000. Disponível em:

<http://www.esev.ipv.pt/mat1ciclo/Resolucao\%20probs/mat450-2001242-seminario-8resolucao_problemas.pdf www.ipv.pt/millenium/17_ect5.htm>. Acesso em: 15 jun. 2016.

POLYA, George. A arte de resolver problemas. Rio de Janeiro, Interciência, 1978.

SILVA, M. G. L.; SILVA, A. F.; NÚÑNEZ, I. B. Dos modelos de mudança conceitual à aprendizagem como pesquisa orientada. In: NÚÑEZ, I.; RAMALHO, B. Fundamentos do ensino-aprendizagem das ciências naturais e da matemática: o novo ensino médio, Porto Alegre: Sulina, 2004, p. 226-244. 